\title{
Experimental Philosophical Aesthetics as Public Philosophy ${ }^{*}$
}

\author{
Aaron Meskin \& Shen-yi Liao \\ Advances in Experimental Philosophy of Aesthetics (in press)
}

Experimental philosophy offers an alternative mode of engagement for public philosophy, in which the public can play a participatory role. ${ }^{1}$ We organized two public events on the aesthetics of coffee that explored this alternative mode of engagement. The first event focuses on issues surrounding the communication of taste. $^{2}$ The second event focuses on issues concerning ethical influences on taste.

In this paper, we report back on these two events which explored the possibility of doing experimental philosophical aesthetics as public philosophy. We set the stage by considering the significance and current state of efforts in public philosophy (section 1), and by introducing the emerging sub-discipline of experimental philosophical aesthetics (section 2). Then, we discuss the research and outreach aspects of the two events on the aesthetics of coffee (section 3 and section 4). Finally, we conclude by reflecting on the prospects and potential pitfalls of experimental philosophy as public philosophy (section 5).

\section{Public Philosophy}

\subsection{Public Philosophy is Valuable}

Public philosophy brings the ideas and practices of academic philosophy to a nonacademic audience. Almost all would agree that public philosophy is a good thing: it allows academic philosophers to make their knowledge and expertise more than just a resource for the privileged few by making it accessible to the many.

There have been a number of recent calls to rethink philosophers' attitudes towards public engagement. For example, in their essay "The Value of Public Philosophy to Philosophers" (2014), Massimo Pigliucci and Leonard Finkelman argue that "public philosophy is a valuable, indeed even vitally necessary, philosophical activity and should be pursued by professional philosophers for both

\footnotetext{
* An earlier version of this chapter, with photographs by Justin Slee, appeared on the Foode_ website. See https://www.foodand.co.uk/articles/experimenting-with-coffee/ . Thanks to Justin, Ross Featherstone of Foode_, Dave Olejnik and the Laynes Espresso team, and Colours May Vary for helping us put on the events. We also had assistance at the two events from Nicholas Watts and Amanosi Ekenimoh: major props to both of them. Thanks also to Counter Culture Coffee for letting use an image of their tasting wheel and to an anonymous reviewer for helpful comments on an earlier draft. This work was supported by a European Community FP7 Marie Curie International Incoming Fellowship, grant PIIF-GA-2012-328977, and by University of Leeds Ignite funding.

${ }^{1}$ Since public philosophy and university teaching both aim to bring the ideas and practices of academic philosophy to a wider audience, some of the points we make will unsurprisingly echo Thomas Nadelhoffer and Eddy Nahmias's "Polling as Pedagogy: Experimental Philosophy as a Valuable Tool for Teaching Philosophy" (2008).

${ }^{2}$ We use the term 'taste' in the everyday broad sense which encompasses both what scientists count as taste and as flavor. For discussion, see Spence, Auvray, and Smith (2014).
} 
practical and theoretical reasons" (87). And although Pigliucci and Finkelman are concerned to establish the theoretical value of public philosophy to philosophers, they are also centrally concerned with the (alleged) external perception of philosophy as useless; this, they argue, can only be changed by philosophers engaging in public outreach.

Similarly, in the blog post "Does Philosophy Matter?" (2015), Walter Sinnott-Armstrong raises concerns about the extent to which philosophers and philosophy are, as he puts it, "out of touch with the rest of society." SinnottArmstrong concludes by suggesting that:

there must be some way for philosophers to show why and how philosophy is important and to do so clearly and concisely enough that non-philosophers can come to appreciate the value of philosophy. There also must be some way to write philosophy in a lively and engaging fashion, so that the general public will want to read it. A few philosophers already do this. Their examples show that others could do it, but not enough philosophers follow their models. The profession needs to enable and encourage more philosophers to reach beyond the profession.

\subsection{Public Philosophy Standardly Operates via a Transmission Model}

To some extent the situation does not seem to be so bad with respect to philosophy and public engagement. In 1999, the Australian Association of Philosophy instituted the AAP Media Prize, designed to honor "the best philosophical piece(s) published by a professional philosopher in the popular media in Australasia", and the American Philosophical Association has been running the Public Philosophy Op-Ed Contest since 2011. The Stone column at The New York Times has been publishing reflections by philosophers and other leading thinkers for a number of years; the Philosophy Talk radio show has been running since 2004; and The Philosopher's

Zone, broadcasted on the Australian Broadcasting Corporation, has run since 2005. The Philosophy Bites podcast continues to release short interviews with leading philosophers, and Peter Adamson's history of philosophy podcast "without any gaps" is up to its 290th episode. ${ }^{3}$ Festivals devoted to (or including) philosophy such as HowTheLightGetsIn and the recent A Night of Philosophy event in New York City have begun to emerge. And the Public Philosophy Journal looks like it is poised to make a major contribution by providing an open-access, peer-reviewed online journal of public philosophy. ${ }^{4}$

As it stands, the vast majority of these valuable public philosophy efforts conform to a fairly traditional mode of public engagement. In most of these cases public engagement consists primarily in the transmission of some information by the philosopher to a largely passive audience. Of course, audience members are sometimes able to ask questions or comment on the material presented, but it cannot be said that these activities are typically participatory. ${ }^{5}$ Although philosophers can

\footnotetext{
3 As of December 6, 2017.

${ }^{4}$ See Pigliucci and Finkelman (2014: 90-92) for discussion of different modes of public philosophy.

${ }^{5}$ As a reviewer pointed out, a plausible exception is public philosophy for children.
} 
provide a valuable service by engaging in such activities, we believe that this is not always the ideal mode in which to teach and learn philosophy. ${ }^{6}$ Like many others in philosophy, we think that "active learning", which engages learners in their own process of learning, is often more pedagogically effective. ${ }^{7}$ As we shall see below, an active approach to public philosophy is possible.

\subsection{Public Philosophy Standardly Operates Distinctly from Research}

In addition, as it stands, public philosophy is often thought of as something distinct from philosophical research; that is, public philosophy is seen as primarily involving the dissemination and popularization of research rather than as being part of the research process itself.

Consider the discussion on the blog Daily Nous that ensued after SinnottArmstrong's blog post (Weinberg 2015). One central theme that emerged in the discussion of this issue was a distinction between philosophical research and public engagement. "I've never seen philosophers criticized for doing public philosophy and I've never copped any flak for doing it myself. As a few people have already noted it doesn't count as research." And "I have not heard good public philosophy denigrated, I don't think ever. Maybe it is useful to explicitly add: public philosophy is typically not research." The standard understanding of public philosophy therefore makes it periphery to "real philosophical work".

We note that this is not always the case in other disciplines. So, for example, the Living Laboratories program at the Museum of Science, Boston, brought child development researchers to the museum in order to run studies which both enhanced public understanding of science and provided the basis for numerous peer-reviewed research publications (Biarnes and Kipling 2013). Another example of this sort of activity was the research on plating orientation at the 'Cravings' exhibition held at London's Science Museum in 2015 (Michel et al 2015).

In our view, it is no accident that public philosophy standardly operates distinctly from research, given that it standardly operates via the transmission model. The public lectures, opinion pieces, podcasts, and radio interviews that comprise the majority of public philosophy are largely devoted to informing the public of relevant philosophical ideas. One-way dissemination makes sense for completed research.

\subsection{Expanding the Scope of Public Philosophy}

Make no mistake, we believe that recent efforts of public philosophy have been tremendously valuable for making public concerns relevant to professional philosophy, and for making professional philosophy relevant to public concerns.

\footnotetext{
${ }^{6}$ Indeed, it is highly questionable whether the transmission model-also known as the banking model-is the best way to teach and learn, period (Freire [1968] 2000).

${ }^{7}$ For a discussion of active learning and an overview of some of the research which supports its effectiveness, see Prince (2004).
} 
Nevertheless, we also believe that the standard modes of operation limit what public philosophy could be.

We believe that the methods of experimental philosophy offer an alternative mode of engagement for public philosophy. The public can play an active role by experiencing and participating in the philosophical project. Moreover, the public events can become part of ongoing research. In this respect, we are agreeing with Eric Schwitzgebel (2015) in recognizing the philosophical value of "[e]ngaging with the world, trying out one's ideas in action, seeing the reactions of non-academics". In two recent public events involving coffee tasting, we aimed to put these ideas for expanding the scope of public philosophy into practice.

\section{Experimental Philosophical Aesthetics}

The projects we undertook were located in the emerging research field of experimental philosophical aesthetics, the sub-branch of experimental philosophy that deals with issue of concern to philosophical aestheticians. ${ }^{8}$ Like many other experimental philosophers, we maintain a broad conception of experimental philosophy-one that includes a variety of methods from the cognitive and social sciences (Rose and Danks 2013). Like many other aestheticians, we maintain a broad conception of aesthetics that include questions that overlap with ethics, epistemology, and many other philosophical subfields (Walton 2007). The diversity of experimental philosophical aesthetics is best illustrated with some of the projects that have been undertaken thus far: Meskin et al (2013) on the mere exposure effect and bad art; Cova and Pain (2013) on folk aesthetics and aesthetic realism; Liao, Strohminger, and Sripada (2014) on the phenomenon of imaginative resistance; and Liao, McNally, and Meskin (2016) and Liao and Meskin (2017) on the linguistic properties of aesthetic adjectives.

The studies we discuss below focus on issues relating to gustatory taste. In fact, both studies have to do with the taste of coffee. Some aestheticians would be hesitant to count issues surrounding gustatory taste as aesthetic (e.g., Scruton 1979). This is a mistake. In the first place, the locus classicus for contemporary discussions of the aesthetic, Kant's Critique of Judgment ([1790] 1987), characterizes a wide notion of the aesthetic which encompasses judgments of agreeability (including tastes "of the tongue, palate and throat") as well as judgments of beauty. In the second place, authors such as Telfer (1996) and Korsmeyer (1999) have presented convincing arguments that experiences and judgments of gustatory taste can count as aesthetic even if we understand that latter category in the narrow sense in which it is often used by contemporary aestheticians. For those who still resist the idea that the study of gustatory judgments falls under the heading of aesthetics, we suggest that our projects could also be seen as located in the emerging research field of philosophy of food (Korsmeyer 1999; Allhoff and Monroe 2007; Kaplan 2012; Meskin 2013; Bramble and Fischer 2016).

\footnotetext{
${ }^{8}$ See Cova, Garcia, and Liao (2015) for an overview of the research field and Torregrossa (in press) for a defense of the research field's viability.
} 


\section{The Communication of Taste}

\subsection{Background}

Our first event focused on the challenge of communicating taste judgments.

Although it has become a commonplace of contemporary philosophy that the word of others is central source of knowledge, philosophical aestheticians have often been skeptical of our capacity to gain aesthetic knowledge by means of what others tell us (Tormey 1973; Whiting 2015). ${ }^{9}$ The same sort of skepticism is often expressed about gustatory judgments. In fact, a number of philosophers have explicitly linked the gustatory with the (narrowly) aesthetic in terms of this feature. Kevin Sweeney, for example, claims that "gustatory judgement, like critical appreciation, must be based on our own sensory experience" (2007: 120).$^{10}$ If this is right, then the testimony of others does not look like it could provide the basis for (warranted) gustatory judgment.

One potential explanation for the failure of aesthetic testimony to transmit knowledge is that aesthetic communication is, in some sense, impossible. We are skeptical of this view. It would be hard to make sense of the persistence of the practices of film, music and restaurant reviews if communication about aesthetic matters were impossible. Our alternative hypothesis is that aesthetic communication is quite difficult. In ordinary circumstances (that is, with normal non-experts in normal conditions), attempting to transmit aesthetic information from one agent to another is an activity that is prone to failure. The difficulty of aesthetic communication is, we suggest, misdiagnosed by those who are skeptical about the transmission of aesthetic knowledge via testimony: they mistakenly treat something that is merely difficult as impossible. In this first event we set out to find support for this view by exploring how difficult it is to transmit gustatory judgments about coffee.

Our research on the communication of taste judgments about coffee is rooted in the work on the language of wine that was begun by Adrienne Lehrer in the 1970s $(1975 ; 2009)$. Lehrer, a linguist, was interested in the nature and function of wine talk and designed a number of studies to explore various features of that domain of discourse. In some of her earliest work on the topic she conducted experiments in which one member of a pair of participants wrote descriptions for three wines belonging to the same broad class (e.g., white table wine) which the other member of the pair then tried to correctly match. Results showed that participants performed no better than chance at matching wines to the correct description. As Lehrer put it, "the communication attempt was unsuccessful" (2009: 110). In various follow-up studies, Lehrer largely confirmed this main finding-"the results showed that one person's matching of wines with a second person's

\footnotetext{
${ }^{9}$ For a response to this skepticism, see Meskin (2004). For an overview of the literature on aesthetic testimony see Robson (2012).

${ }^{10}$ For a similar view, see Korsmeyer (2013: 258-259). For criticism of this sort of view, see Meskin and Robson (2015).
} 
descriptions was not generally better than chance" (2009: 155) and this was even the case with subjects who were scientists at the Department of Viticulture and Enology at University of California at Davis. ${ }^{11}$ Lehrer concluded from this early work that much wine talk was phatic; that it is used to create and maintain social bonds rather than to communicate taste information. Although this is an interesting hypothesis in its own right, we were more interested in Lehrer's main finding and the methods that she used.

Moreover, there has been a great deal of research following up on, and extending, Lehrer's wine studies. Lawless (1987) recreated Lehrer's experiment and found that expert wine drinkers were significantly better than novices at correctly matching flavor descriptions to the correct wine. Hughson and Boakes (2002) found that participants were better at correctly matching wines to flavor descriptions when given a small list of 14 wine terms rather than a long list of 125 wine terms or no list at all. Solomon (1990) tested the ability of experts and novices to correctly match flavor description written by other novices and experts. It was only when experts matched descriptions written by other experts that they performed better than chance. In brief, it appears that research largely supports Lehrer's claims that untrained folk find communication about wine very difficult, but it also suggests that experts may be better at such communication than her early results suggested.

Using a version of Lehrer's experimental paradigm, would we find that ordinary folk could successfully communicate the flavors of coffee?

\subsection{Event}

In February 2015, we held a public event on the communication of coffee at Colours May Vary design and print shop in Leeds, in collaboration with the online food journal Food\&_(foodand.co.uk). Twenty-four people paid 5 GBP to participate in the event. Our experimental design was based on Lehrer's earliest wine communication experiments described above.

The participants were split into two groups (each $n=12$ ). The first group ("describers") was sequentially presented with small cups of three distinct coffees. Two of the coffees came from the same farm in El Salvador using the same Kenia and Bourbon beans but processed differently (either washed or natural) to give related but distinct flavors. The third coffee came from Rwanda using heirloom and Bourbon beans. Coffees were batch brewed by Laynes Espresso, a well-regarded Leeds coffee shop, and kept at the same temperature to ensure taste consistency.

\footnotetext{
${ }^{11}$ It is, however, the case that those subjects did do significantly better than chance in a matching experiment run later by one of those UC-Davis subjects.
} 


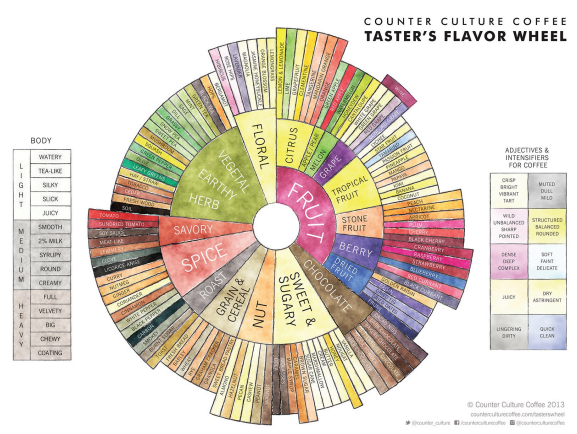

Figure 1. Counter Culture Coffee's flavor wheel. Courtesy Counter Culture Coffee.

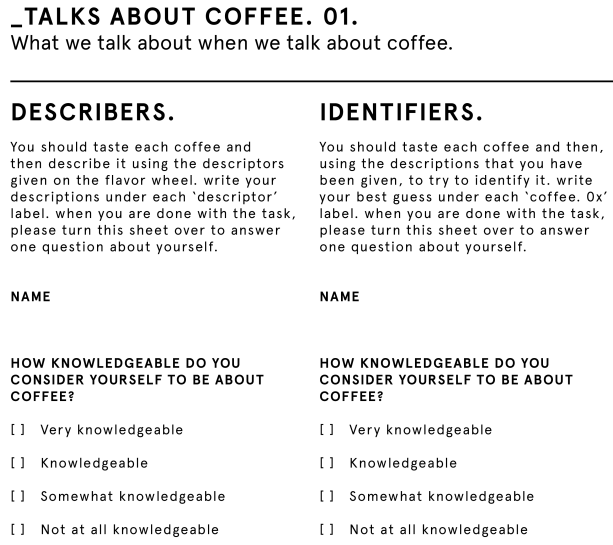

COFFEE. $02 . \quad$ DESCRIPTORS.

COFFEE. 03.

DESCRIPTORS.

Figure 2. Material for participants at the communication of taste event. 
Describers were also given Counter Culture Coffee's flavor wheel (Figure 1) and a form with spaces to describe each coffee (Figure 2). We recommended to the describers that they use the more basic descriptors in the center of the wheel (such as 'floral', 'earthy', 'nut' or 'spice') rather than the more specific descriptors on the outside (such as 'burnt sugar' or 'dried fig') but they were told that they were free to describe the coffees as they saw fit. ${ }^{12}$ Describers were given five minutes to taste and describe each coffee.

The second group ("identifiers") were also presented with the three coffees (served sequentially) and the flavor wheel. In addition, each identifier received a completed form from one randomly-assigned describer. Identifiers were then asked to correctly match the descriptions with the coffees. Identifiers were also given five minutes to taste and identify each coffee.

The results surprised us. Not only did participants do no better than chance at matching coffee to descriptions, they actually did worse than chance. Out of twelve participant pairs, none correctly identified all coffee tasted, four correctly identified one coffee tasted, and the remaining eight correctly identified none of the coffee tasted. (For comparison, if participants simply guessed at random, we would have expected that out of twelve participant pairs, two would correctly identify all coffee tasted, six would correctly identify one, and four would correctly identify none.) The difference between the actual response we found and chance is statistically significant, $X^{2}(2)=6.667, p=0.036$. This result suggests that it is very difficult for people to communicate about coffee tastes. Of broader significance, this result suggests that aesthetic communication could indeed be quite difficult.

\subsection{Public Philosophy}

In addition, this event also demonstrated that experimental philosophical aesthetics is an effective mode of public philosophy. Not only were the people at this event participants of an experimental study, they were also participants in a public philosophy dialogue. After the result was revealed, they were given the opportunity to interpret the result and discuss its philosophical significance.

Dave Olejnik, head barista of Laynes Espresso, thought that he could have chosen the coffees so that everyone identified all three perfectly. This led to a discussion of whether this result really provides any reason to think that communication about coffee is difficult or, instead, that our results were just an artifact of the particular set of coffees used. In addition, although we had recommended to the participants that they use the more basic descriptors in the center of the flavor wheel rather than the more specific descriptors on the outside, many admitted to not following our advice. The crowd then engaged in interesting discussion about why they might not have followed our advice and how that could have influenced the result. ${ }^{13} \mathrm{~A}$ number of participants suggests various subjectivist or

\footnotetext{
${ }^{12}$ The main flavour wheel has 20 distinct flavor categories in the center (some of which contain more than one descriptor) and 120 on the outside. There are additional descriptors for body, faults, and 'adjectives \& intensifiers'.

${ }^{13}$ Some studies suggest that people are better at communicating about the taste of wine when they are presented with a short list of wine terms rather than a long list (Hughson and Boakes, 2002).
} 
relativist interpretations of the result, and this led to another interesting discussion about what the point of giving tasting notes might be, if communication about coffee tastes was really so difficult. In short, the people who attended the event were not just passive recipients of philosophy, but participants in philosophizing.

\section{Ethical Influence on Taste}

\subsection{Background}

Philosophers have long debated the connection between the moral value and the aesthetic value, primarily focusing on artworks. ${ }^{14}$ How do ethical aspects of an artwork influence aesthetic judgments? With some nuances, the debate on the interaction between morality and aesthetics in art can be extended to apply to food. ${ }^{15}$ For our purpose here, we will focus on two views. Food moralism says that a food's moral value is directly connected to its aesthetic value. Food autonomism says that a food's moral value is unconnected to its aesthetic value. If people were food moralists, then we would expect that learning morally positive information about the coffee would make it taste better to them. Conversely, if people were food autonomists, then we would expect that learning morally positive information about the coffee would make no difference to how it tastes to them.

There is very limited empirical research on ethical influences on people's taste perception. And only two articles specifically address this influence with coffee. De Pelsmacker, Driesen, and Rayp (2005) found that consumers are willing to pay more for fair trade coffee, but at a premium below the typical markup. However, they do not directly address perception and experience of tasting coffee. Sörqvist et al (2013) presented participants with two cups of coffee, one of which is unlabeled and the other is labeled as eco-friendly, even though they were in fact qualitatively identical. Across three studies, they found that found that participants who have sustainability-congruent attitudes rate "eco-friendly" coffee as tastier. They thus conclude that "Eco labels not only promote a willingness to pay more for the product but also lead to a more favorable perceptual experience of it" (Sörqvist et al 2013: 1).

\subsection{Event}

In March 2015, we held another public event-this time, on the ethical influence on taste_-again at Colours May Vary and in collaboration with Food\&_ and Laynes Espresso. Twenty people paid 5 GBP to participate in the event. Our experimental design was inspired by Sörqvist et al (2013), but with two important modifications.

First, instead of a within-subject design, we employed a between-subject design. So, we divided up participants into two groups, one in the morally neutral condition $(n=11)$ and the other in the morally positive condition $(n=9)$. The coffee was batch brewed and kept at a constant temperature. Participants in the morally

\footnotetext{
${ }^{14}$ See Eaton (2016), Giovanelli (2007), and McGregor (2014) for recent overviews of the debate.

${ }^{15}$ See Liao and Meskin (in press) on the interaction between morality and aesthetics in food. See Korsmeyer (2012)

for arguments for food moralism and against food autonomism.
} 
neutral condition did the tasting first, while the other participants engaged in an unrelated activity.

Second, instead of an eco-labeling manipulation, we manipulated participants' moral attitudes toward the coffee producers' work conditions. So, participants in the morally positive condition received the following text prior to their coffee tasting (the bolded parts are the additions to the information given to participants in the morally neutral condition):

Square Mile in London roasted the coffee beans used. The beans are a mix of Bourbon and Kenia varieties. They were produced in El Salvador and wet processed. The farm owner is very welfare conscientious: she pays the workers $50 \%$ above minimum wage and provides social services, such as medical care, for their families.

They then answered the question "What do you think of the taste of the coffee?" on a 7-point unnumbered scale from "among the worst I've tasted" on the left to "among the best I've tasted" on the right (figure 3). 


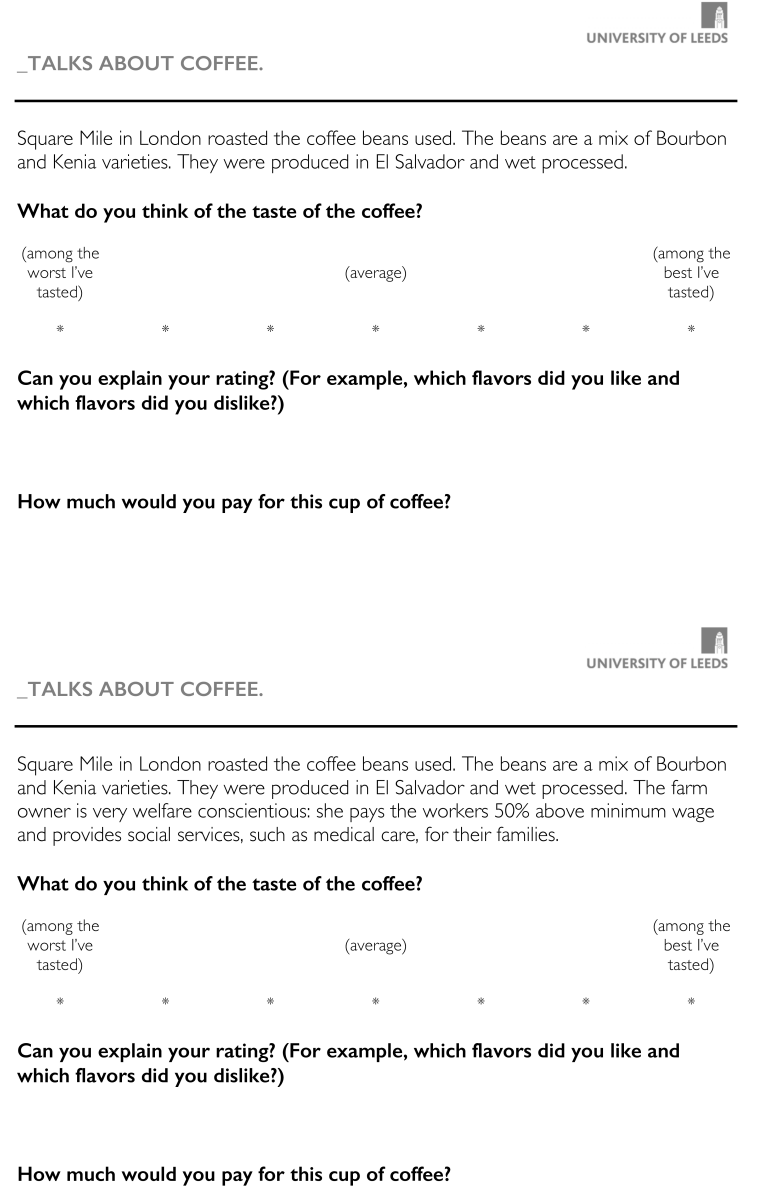

Figure 3. Material for participants at the ethical influence on taste event.

While the responses were being collected and analyzed by our research assistants, participants were given a brief primer on the philosophical debate on the interaction between morality and aesthetics, especially with respect to food. And then the results were revealed to everyone at the same time. 

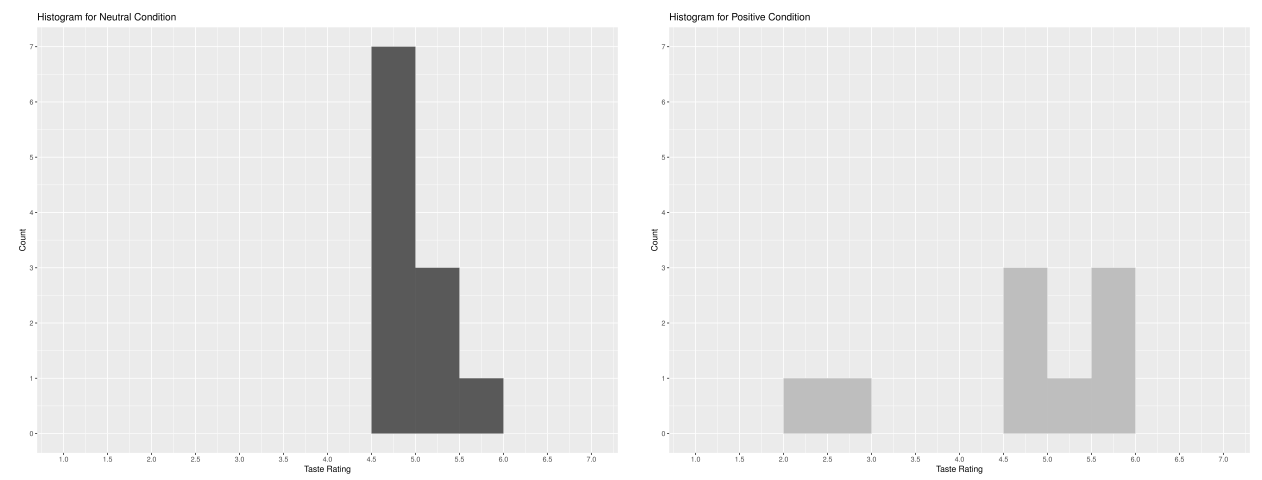

Figure $4 a$ and $4 b$. Taste ratings at the ethical influence on taste event.

Contrary to our expectations, we did not find an ethical influence on people's taste of coffee. In fact, the morally neutral condition group $(M=5.23 ; S D=$ 0.343 ; figure $4 \mathrm{a}$ ) thought the coffee tasted better than the morally positive condition group $(M=4.89 ; S D=1.294$; figure $4 \mathrm{~b})$ did, but the difference is not statistically significant, $t(8)=0.763, p=0.467 .{ }^{16}$ However, given that the study only has relatively few participants, we hesitate to say anything definitive on the basis of this nonsignificant result.

\subsection{Public Philosophy}

Still, the result was good for generating discussion. The participants were briefly told about potential explanations due to experimental artifacts, such as the relatively low number of participants and the difference in study design, and then asked to think about why we found this result. Some participants made interesting empirical conjectures. For example, one thought many participants already have positive associations with the coffee provider, which could lead them to assume positive moral standing of the coffee served. And, as such, even in the morally neutral condition the assumed positive moral standing remained on participants' minds during tasting. Other participants drew on their own experiences to theorize about the results. For example, one made the fine distinction between how something tastes and the experience of tasting something, and conjectured that although positive moral information can raise the experience of tasting something (e.g. make you want to go to a shop again), it cannot change how something tastes. The experimental results, and participation in this exercise, thus gave participants an opportunity to draw on seemingly mundane experiences (like drinking coffee!) to philosophize about the complicated relationship between ethics and taste.

\footnotetext{
${ }^{16}$ Participants' responses to the question of how much they'd pay for the cup of the coffee showed the same pattern.
} 


\section{Prospects and Potential Pitfalls}

As we highlighted at the start, nearly everyone agrees that public philosophy is valuable. But standard approaches, which operate via the transmission model and present already completed philosophical research, have drawbacks. We hope that, by sharing our experiences in organizing these two public events on the aesthetics of coffee, we have shown that experimental philosophy-perhaps especially experimental philosophical aesthetics - can be a way to expanding the scope of public philosophy. Specifically, we think the methods of experimental philosophy can be incorporated into public philosophy to encourage more two-way interactions between the academic philosopher and the public, and to integrate the aims of outreach and research.

Still, we would be remiss to not mention some trade-offs and limitations. An advantage of the transmission model is that it allows philosophical ideas to reach many people with a single effort. In contrast, our public events were necessarily limited to relatively few participants in order to preserve interactivity. Moreover, the transmission model is applicable to a wider range of audiences. In contrast, given that experiments were central to our public events, ethical considerations make them unsuitable for people in vulnerable circumstances, such as prisoners and children. We must keep these potential pitfalls in mind in conducting experimental philosophy as public philosophy.

The recognition of the prospects and the potential pitfalls of experimental philosophy as public philosophy underscores the necessity of methodological pluralism in public philosophy. Different audiences, considerations and contexts call for different models. 


\section{References}

Allhoff, F. and Monroe, D., eds. (2007), Food \& Philosophy: Eat, Think, and Be Merry, Malden, MA: Wiley-Blackwell.

Biarnes, M. and Kipling, B. (2013), 'A great match: Psychological scientists and museum educators', Psychological Science Agenda, November. Available online at

http://www.apa.org/science/about/psa/2013/11/researchers-educators.aspx (accessed 15 June 2017).

Bramble, B. and Fischer, B, eds. (2016), The Moral Compexities of Eating Meat, New York: Oxford. University Press.

Cova, F., Garcia, A., and Liao, S. (2015), 'Experimental Philosophy of Aesthetics', Philosophy Compass 10(12): 927-939.

Cova, F. and Pain, N. (2013), 'Can Folk Aesthetics Ground Aesthetic Realism', The Monist 95(2): 241-263.

De Pelsmacker, P., Driesen, L., and Rayp, G. (2005), 'Do Consumers Care about Ethics? Willingness to Pay for Fair-Trade Coffee', The Journal of Consumer Affairs 39(2): 363-385.

Eaton, A. W. (2016), 'Literature and Morality', in N. Carroll and J. Gibson (eds.), The Routledge Companion to Philosophy of Literature, New York: Routledge, 433-450.

Freire, P. ([1968] 2000), Pedagogy of the Oppressed, $30^{\text {th }}$ Anniversary Edition, New York: Continuum.

Giovanelli, A. (2007), 'The Ethical Criticism of Art: A New Mapping of the Territory', Philosophia 35: 117-127.

Hughson, A. \& Boakes, R. A. (2002), 'The knowing nose: the role of knowledge in wine expertise', Journal of Food Quality and Preference 13: 463-472.

Kant, I. ([1790] 1987), Critique of Judgment, translated by Werner Pluhar, Indianapolis: Hackett.

Kaplan, D. (2012), The Philosophy of Food, Berkeley: University of California Press.

Korsmeyer, C. (1999), Making Sense of Taste: Food and Philosophy, Ithaca, NY: Cornell University Press.

Korsmeyer, C. (2012), 'Ethical Gourmandism,' in D. M. Kaplan (ed.), The Philosophy of Food, Berkeley: University of California Press, 87-102.

Korsmeyer, C. (2013), 'Taste', in B. Gaut and D. M. Lopes (eds.), The Routledge Companion to Aesthetics, 3rd ed., New York: Routledge, 257-266. 
Lawless, H. T. (1987), 'Flavor Description of White Wine by "Expert" and Nonexpert Wine Consumers', Journal of Food Science 40: 120-123.

Lehrer, A. (1975), 'Talking about Wine’, Language 51 (4): 901-923.

Lehrer, A. (2009), Wine and Conversation, $2^{\text {nd }}$ edition, New York: Oxford University Press.

Liao, S., McNally, L., and Meskin, A. (2016), 'Aesthetic Adjectives Lack Uniform Behavior', Inquiry 59(6): 618-631.

Liao, S. and Meskin, A. (2017), 'Aesthetic Adjectives: Experimental Semantics and ContextSensitivity', Philosophy and Phenomenological Research 94(2): 371-398.

Liao, S. and Meskin, A. (in press), 'Morality and Aesthetics of Food', in A. Barnhill, M. Budolfson, and T. Doggett (eds.), The Oxford Handbook of Food Ethics, New York: Oxford University Press.

Liao, S., Strohminger, N. and Sripada, C. S. (2014), 'Empirically Investigating Imaginative Resistance', British Journal of Aesthetics 54(3): 339-355.

McGregor, R. (2014), 'A Critique of the Value Interaction Debate', British Journal of Aesthetics 54(4): 449-466.

Meskin, A. (2004), 'Aesthetic Testimony: What Can We Learn From Others About Beauty and Art?', Philosophy and Phenomenological Research 69 (2004): 65-91.

Meskin, A. (2013), 'The Art of Food', The Philosopher's Magazine 61, 2013: 81-86.

Meskin, A., Phelan, M., Moore, M., and Kieran M. (2013), 'Mere Exposure to Bad Art', British Journal of Aesthetics 53(2): 139-164.

Meskin, A, and Robson, J. (2015), 'Taste and Acquaintance', The Journal of Aesthetics and Art Criticism 73(2): 127-139.

Michel, C., Woods, A. T., Neuhäeuser, M., Landgraf, A., and Spence, C. (2015), 'Rotating plates: Online study demonstrates the importance of orientation in the plating of food', Food Quality and Preference 44: 194-202.

Pigliucci, M. and Finkelman, L. (2014), 'The Value of Public Philosophy to Philosophers', Essays in Philosophy 15(1): 86-102.

Prince, M. (2004), 'Does Active Learning Work? A Review of the Research', Journal of Engineering Education 93(3): 223-231.

Robson, J. (2012), 'Aesthetic Testimony', Philosophy Compass 7(1): 1-10.

Rose, D., and Danks, D. (2013), 'In defense of a broad conception of experimental philosophy', Metaphilosophy 44: 512-532. 
Schwitzgebel, E. (2015), 'What Philosophical Work Could Be', The Splintered Mind, 11 June. Available online at https://schwitzsplinters.blogspot.com/2015/06/what-philosophical-workcould-be.html (accessed 21 June 2015).

Scruton, R. (1979), The Aesthetics of Architecture, Princeton NJ: Princeton University Press.

Sinnott-Armstrong, W. (2015) 'Does Philosophy Matter?' Daily Nous, 3 March. Available online at http://dailynous.com/2015/03/03/does-philosophy-matter-guest-post-by-waltersinnott-armstrong/ (accessed 21 June 2015).

Solomon, G. E. A. (1990), 'Psychology of Novice and Expert Wine Talk', American Journal of Psychology 103(4): 495-517.

Sörqvist, P., Hedblom, D., Holmgren, M., Haga, A., Langeborg, L., Nöstl, A., and Kågström, J. (2013), 'Who Needs Cream and Sugar When There Is Eco-Labeling? Taste and Willingness to Pay for "Eco-Friendly" Coffee', PLoS ONE 8(12): e80719.

Spence C., Auvray M., and Smith, B. (2015), 'Confusing Tastes and Flavours', in D. Stokes, M. Matthen, and S. Biggs (eds.), Perception and its modalities, Oxford, UK: Oxford University Press, 247-274.

Stecker, R. (2005), 'The Interaction Between Ethical and Aesthetic Value', British Journal of Aesthetics 45(2): 138-150.

Sweeney, K. W. (2007), 'Can a Soup Be Beautiful? The Rise of Gastronomy and the Aesthetics of Food', in F. Allhoff and D. Monroe (eds.), Food \& Philosophy: Eat, Think, and Be Merry, Malden, MA: Wiley-Blackwell, 117-132.

Telfer, E. (1996), Food for Thought: Philosophy and Food, London: Routledge.

Tormey, A. (1973), 'Critical Judgments', Theoria 39: 35-49.

Torregrossa, C. (in press), 'A Defence of Experimental Philosophy in Aesthetics', Inquiry.

Walton, K. (2007), 'Aesthetics-What? Why? and Wherefore?', The Journal of Aesthetics and Art Criticism 65: 147-161.

Weinberg, J. (2015), 'Reputational Cost of Public Philosophy?', Daily Nous, 5 March. Available online at http://dailynous.com/2015/03/05/reputational-cost-of-public-philosophy/ (accessed 22 June 2015).

Whiting, D. (2015), 'The Glass is Half Empty: A New Argument for Pessimism about Aesthetic Testimony', British Journal of Aesthetics 55(1): 71-89. 